\title{
The Gardens of Taj Mahal and the Sun
}

\section{Amelia Carolina Sparavigna'}

1Department of Applied Science and Technology, Politecnico di Torino, Italy

\begin{abstract}
The Taj Mahal is a splendid mausoleum in Agra, Uttar Pradesh, India, built by the Mughal emperor Shah Jahan. It is the best known and famous example of the Mughal architecture, which combines elements from Islamic and Indian architectural styles. Here we discuss the planning of the Taj Mahal gardens and their orientation with sunrise/sunset azimuths on solstices.
\end{abstract}

Keywords: Satellite Maps, Solar Orientation, Archaeoastronomy

\section{Introduction}

One of the subjects of archaeoastronomical researches is that of understanding the role the sky had in ancient cultures. A source of information for these researches is the analysis of the alignments of archaeological sites towards an astronomical target, such as the rising sun, the moon or some stars [1-5]. This alignment is given by measuring the azimuth, the angle from North on the horizontal plane. To compare it with sunrise or sunset azimuths, we can use several tools freely available on the Web: one of them is provided by Sollumis.com and allows observing the direction and altitude of the sun on each day of the year, represented by a diagram on a satellite Google map. Using it, we were able to find that the Lion Rock complex in Sri Lanka is oriented with the sunset on the day the sun reaches the zenith, that is, the altitude of 90 degrees [6].

Besides the cases of some prehistoric sites, we observed a solar alignment in the planning of ancient Chinese towns, such as Shangdu, the summer capital of Kublai Khan, Xi'an and Khanbalik [7]. These towns have their main axis aligned in the NorthSouth direction, but some elements of their planning are given according to the sunrise and sunset azimuths on solstices. Even in the planning of the buildings of the Forbidden City of Beijing, we find such a solar orientation [7]. Here, we will discuss another example, where the architectural complex is aligned in the North-South direction, but it containing also an orientation with the Sun. It is the garden of the Taj Mahal, the finest example of Mughal architecture.

\section{Taj Mahal}

The Taj Mahal, the Crown of Palaces, is a splendid white mausoleum in Agra, Uttar Pradesh, India. The Mughal emperor Shah Jahan built it in memory of his third wife, Mumtaz Mahal. The Taj Mahal is the best known and famous example of the Mughal architecture, which combined elements from Islamic and Indian architectural styles [8,9]. The mausoleum is one of the components of a quite large complex of structures, composed by buildings and gardens, including subsidiary tombs, waterworks infrastructure, the small town of Taj Ganji and a Moonlight Garden, north of the River Yamuna. The construction began in $1632 \mathrm{AD}$ and was completed around $1653 \mathrm{AD}$. A board of architects under imperial supervision worked to the Taj Mahal, among them there were Abd ul-Kari, Ma'mur Khan, Makramat Khan, and Ustad Ahmad Lahauri [10]. Lahauri is generally considered the principal designer of the complex. In the Figure 1 we can see a satellite image from Google Earth of the site and below a plan of it. On the left, we find the Moonlight Garden, north of River Yamuna. Then we have the Mausoleum, with a Mosque and a Jawab. After, we find the Charbagh gardens: a gateway is connecting the gardens with the Taj Ganji. The mausoleum is the central focus of the entire complex, a large, white marble structure. 


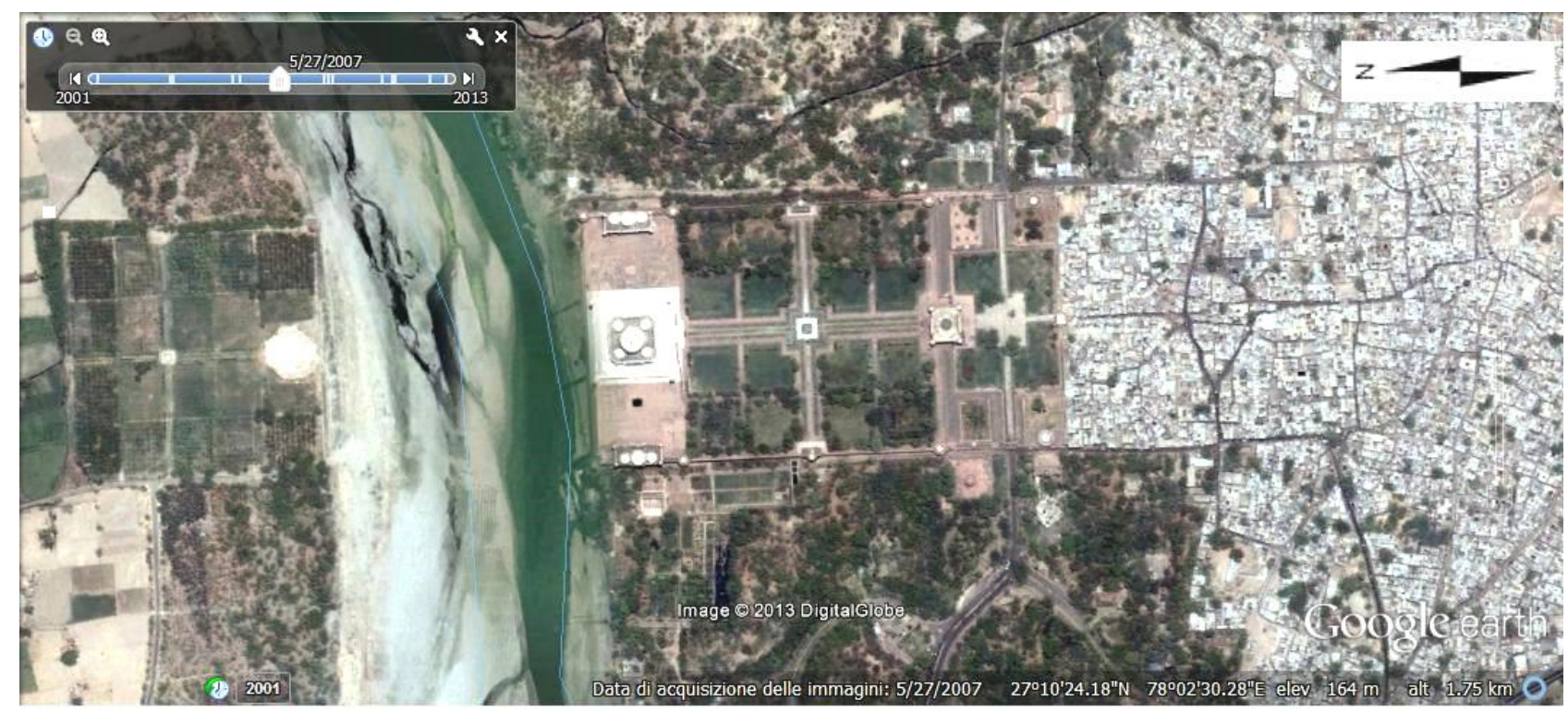

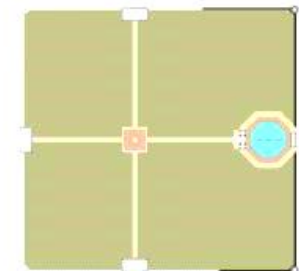

Moonlight Garden north River Yamuna

\section{Tomb, Mosque and Jawab}

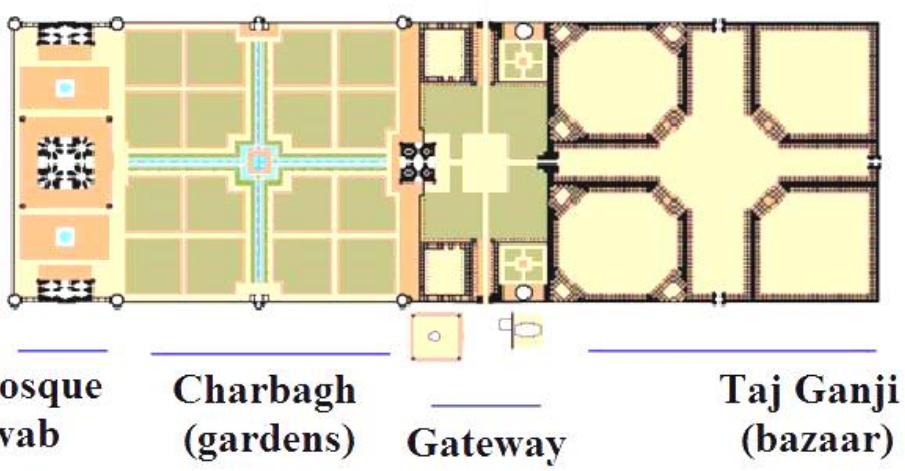

Figure 1 - The Taj Mahal complex. It is aligned in the North-South cardinal direction. Courtesy: Google Earth and Wikipedia.

\section{The Paradise Gardens}

The "charbagh" is the Mughal garden, composed by raised pathways that divide the garden in four parts and each of these four quarters into sixteen sunken parterres or flowerbeds (Figure 2). A marble water tank at the center of the garden, halfway between the tomb and gateway, along the North-South axis, reflects the image of the mausoleum. The charbagh garden is modeled on the Persian gardens: it was introduced to India by the first Mughal emperor, Babur [10,11]. Its planning symbolizes the Paradise, the "Garden of Eden". The word "paradise" is coming from the Latin "paradisus" and from the Greek "paradeisos", however it has an Iranian source "pairidaeza", which indicates a park in an enclosure, that is, a walled garden [12]. In mystic Islamic texts of Mughal period, the Paradise is described as an ideal garden of abundance with four rivers flowing from a central spring or mountain along the four cardinal directions [10]. In their ideal form then, the charbagh gardens were laid out as a square or rectangle subdivided into four equal parts; the rivers were represented by shallow canals which separate the garden by flowing towards the cardinal points. However, it is necessary to remark that the cross axial garden also finds independent precedents within South Asia in the royal gardens of Sigiriya in Sri Lanka $[13,14,6]$ : in this case, the orientation of the garden is not coincident with cardinal directions [6]. 


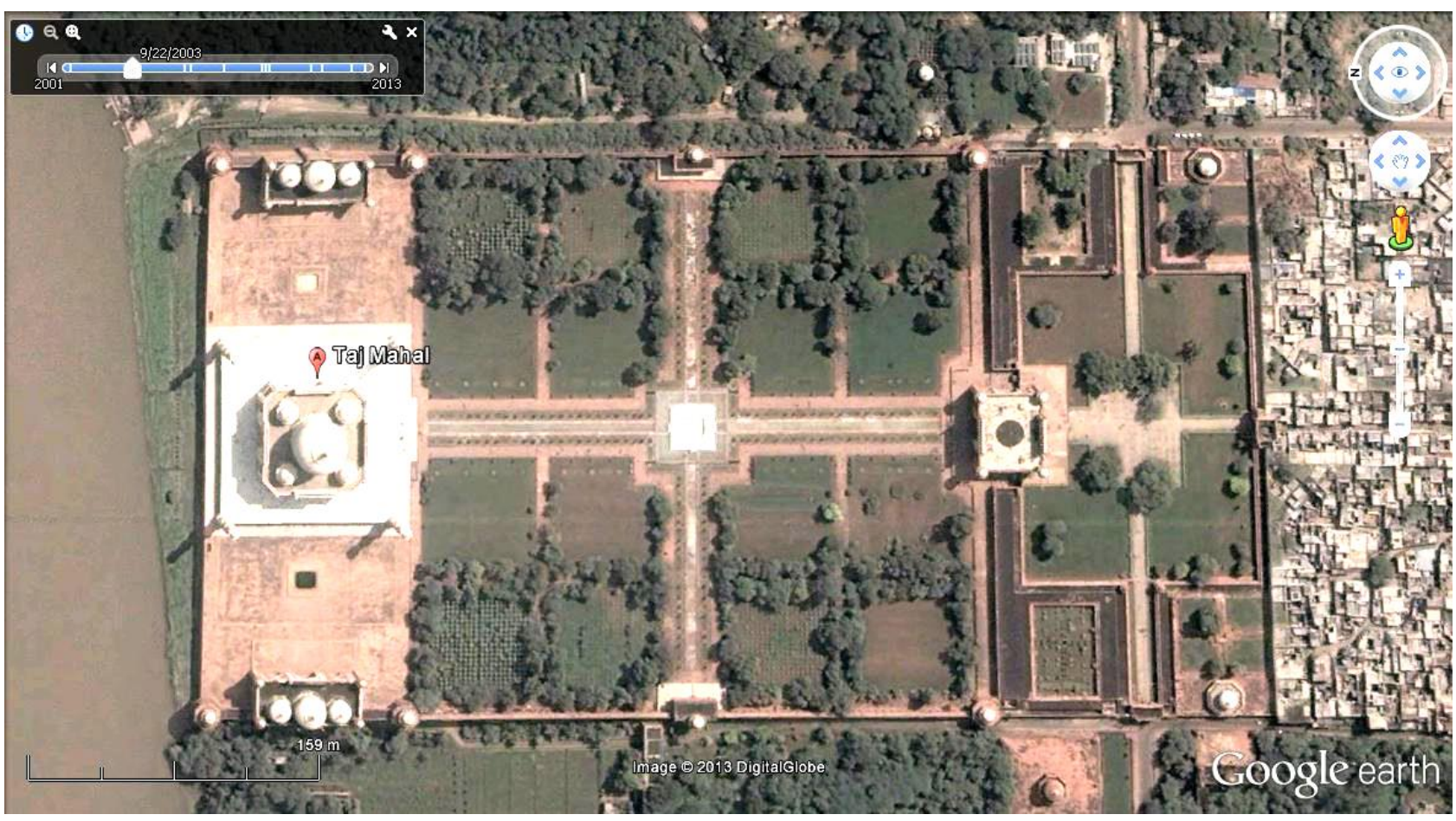

Figure 2 - The Taj Mahal Gardens. Note that the image is rotated: the mausoleum, gardens and gateway are aligned in the North-South cardinal direction.

According to Ref.10, most Mughal charbaghs are rectangular with a tomb or pavilion in the center. The Taj Mahal garden is unusual because its main element, the white Mausoleum, is located at the end of the garden. This fact created a debate amongst scholars regarding the reasons why the traditional charbagh form had not been used. Ebba Koch suggests that a variant of the charbagh was employed; that of the more secular waterfront garden found in Agra, adapted for a religious purpose $[10,14]$. However, after the discovery of the Moonlight Garden, on the other side of the River Yamuna, the Archaeological Survey of India proposed that the Yamuna itself was incorporated into the planning of Taj Mahal, to be seen as one of the rivers of Paradise. In this case, the Taj Mahal complex, as shown in the Figure 1, becomes the traditional charbagh [10].

\section{The Garden and the Sun}

In Ref.15, a detailed discussion of the symbols involved in the architectural planning of the Taj Mahal garden and in its decorative elements is proposed. Here, we want to show another possible interpretation of the planning of the garden, according to sunset and sunrise azimuths.

As we have discussed in the Ref.7, some ancient Chinese towns are aligned in the cardinal NorthSouth direction, the projection on the horizontal plane of the "axis mundi", the axis about which the world is rotating. However, in planning them, architects used some elements aligned in the directions of sunrises and sunsets on solstices. Another example discussed in [7], is a court of the Forbidden City in Beijing, that having at its centre the Hall of the Central Harmony, between the Halls of Preserving Harmony (North) and Supreme Harmony (South). This court is aligned in the NorthSouth direction, but, from the Hall of the Central Harmony, we can see the sun rising and setting exactly at the corners of the northern edge on the summer solstice, and at those of the southern edge on the winter solstice. In such a manner, this enclosure becomes a symbolic horizon, aligned in the direction of the "axis mundi", at the corners of which the sun is rising and setting on solstices.

This is the same for the garden of the Taj Mahal. Let us observe the Figure 3, showing the northern part of the garden and the direction of the Sun, viewed from its centre, as depicted by the diagrams of Sollumis.com. Note that at the corners of this rectangular part of the garden, we have white pavilions. On the winter solstice, the sun rises and sets at the southern corners of the garden (upper image). On the summer solstice, the sun rises and sets exactly at the northern corners (lower image). The same happens to the southern part of the garden. We can then repeat what we observed about the court of the Forbidden City: the enclosure of the garden becomes a symbolic horizon, where we have an alignment of the planning in the direction of the "axis mundi", and the corners are placed in such a manner that we can see, from the centre of the enclosure, the sun rising and setting there on the solstices. 

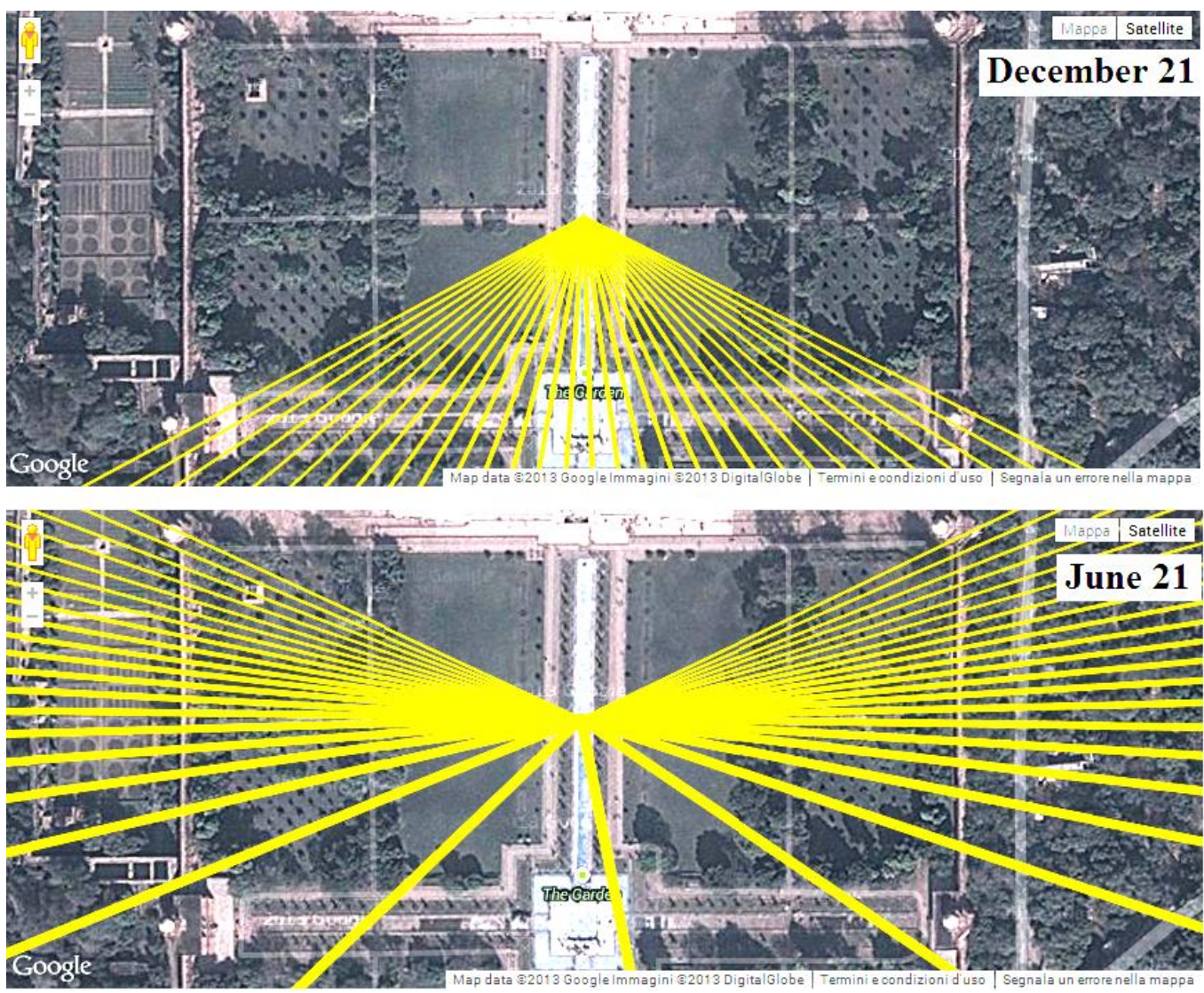

Figure 3 - The northern part of the garden of Taj Mahal. We can see the direction of the sun during the winter and summer solstices, given by Sollumis.com (http://www.sollumis.com/). This site provides a polar diagram, overlaying a satellite map, showing the directions of the sun for any day of the year. The lines on the drawing show the direction and height (altitude) of the sun. Thicker lines mean the sun is higher in the sky. Longer and thinner lines mean the sun is closer to the horizon.

\section{Conclusion}

The Taj Mahal complex was created with some symbolic meanings. The Gardens for instance are representing the "Garden of Eden", according to the mystic texts of the Mughal period, with four canals flowing from a central spring in the four cardinal directions. Here, we have shown that these gardens could have been planned according to the sunset and sunrise azimuths on solstices too. We have already discussed in a previous paper an example of a court having such a design, that of the Hall of the Central Harmony in the Forbidden City of Beijing [7]. The same happens to the gardens of Taj Mahal, so that the enclosures of them become a symbolic horizon. This horizon has the main alignment in the direction of the axis of the world, and its corners located in such a manner that it is possible to see the sun rising and setting there on the solstices.

\section{References}

1. A.C. Sparavigna, The Chinese Pyramids and the Sun, arXiv:1211.0915.

2. A.C. Sparavigna, Stone Circles on the Harraat of Syrian Desert, arXiv: 1208.2591 .

3. A.C. Sparavigna, The Sunrise Amplitude Equation Applied to an Egyptian Temple, arXiv:1207.6942.
4. A.C. Sparavigna, Maria Reiche's Line to Archaeoastronomy, arXiv: 1210.1170.

5. A.C. Sparavigna, On the Solar Orientation of Ales Stenar Site, Scribd, 13 May 2013.

6. A.C. Sparavigna, The Solar Orientation of the Lion Rock Complex in Sri Lanka, The International Journal of Sciences, 2013, Volume 2, Issue 11, Pages 60-62.

7. A.C. Sparavigna, Sunrise and Sunset Azimuths in the Planning of Ancient Chinese Towns, The International Journal of Sciences, 2013, Volume 2, Issue 11, Pages 52-59.

8. Ebba Koch, Mughal Architecture: an Outline of Its History and Development, Oxford University Press, 2002.

9. Lesley A. Dutemple, The Taj Mahal, Lerner Publishing Group, 2003.

10. Wikipedia, Taj Mahal, http://en.wikipedia.org/wiki/Taj_Mahal, and references therein.

11. Wikipedia, Mughal gardens, http://en.wikipedia.org/wiki/Mughal_gardens, and references therein.

12. Douglas Harper, Online Etymology Dictionary, 2013, http://www.etymonline.com/index.php

13. Wikipedia, Origins and Architecture of the Taj Mahal, and references therein

14. Ebba Koch, The Complete Taj Mahal: And the Riverfront Gardens of Agra, Thames \& Hudson Ltd., 2006.

15. Wayne E. Begley, The Garden of the Taj Mahal: A Case Study of Mughal Architectural Planning and Symbols, in James L. Wescoat, Jr. and Joachim Wolschke-Bulmahn Editors, Mughal Gardens: Sources, Places, Representations, and Prospects, Washington DC, Dumbarton Oaks, 1996, Pages 213-231 